\title{
Diabetes-Related Induction of the Heme Oxygenase System and Enhanced Colocalization of Heme Oxygenase 1 and 2 with Neuronal Nitric Oxide Synthase in Myenteric Neurons of Different Intestinal Segments
}

\author{
Lalitha Chandrakumar, Mária Bagyánszki, Zita Szalai, Diána Mezei, and Nikolett Bódi \\ Department of Physiology, Anatomy and Neuroscience, Faculty of Science and Informatics, University of Szeged, Közép fasor 52, \\ Szeged H-6726, Hungary \\ Correspondence should be addressed to Nikolett Bódi; bodiniki85@gmail.com
}

Received 25 April 2017; Revised 2 August 2017; Accepted 17 August 2017; Published 10 September 2017

Academic Editor: Saeid Golbidi

Copyright (C) 2017 Lalitha Chandrakumar et al. This is an open access article distributed under the Creative Commons Attribution License, which permits unrestricted use, distribution, and reproduction in any medium, provided the original work is properly cited.

\begin{abstract}
Increase in hyperglycaemia-induced oxidative stress and decreased effectiveness of endogenous defense mechanisms plays an essential role in the initiation of diabetes-related neuropathy. We demonstrated that nitrergic myenteric neurons display different susceptibilities to diabetic damage in different gut segments. Therefore, we aim to reveal the gut segment-specific differences in the expression of heme oxygenase (HO) isoforms and the colocalization of these antioxidants with neuronal nitric oxide synthase (nNOS) in myenteric neurons. After ten weeks, samples from the duodenum, ileum, and colon of control and streptozotocin-induced diabetic rats were processed for double-labelling fluorescent immunohistochemistry and ELISA. The number of both $\mathrm{HO}$-immunoreactive and nNOS/HO-immunoreactive myenteric neurons was the lowest in the ileal and the highest in the colonic ganglia of controls; it increased the most extensively in the ileum and was also elevated in the colon of diabetics. Although the total number of nitrergic neurons decreased in all segments, the proportion of nNOS-immunoreactive neurons colocalizing with HOs was enhanced robustly in the ileum and colon of diabetics. We presume that those nitrergic neurons which do not colocalize with HOs are the most seriously affected by diabetic damage. Therefore, the regional induction of the $\mathrm{HO}$ system is strongly correlated with diabetes-related region-specific nitrergic neuropathy.
\end{abstract}

\section{Introduction}

There has been a dramatic increase in the incidence of various metabolic diseases, like hypertension, obesity, or diabetes, globally [1-3]. Diabetes mellitus has long been recognized as the major risk factor of cardiovascular diseases. Intensive glycemic control has reduced the risks of macroand microvascular complications of diabetes; however, cardiovascular events remain the leading risk factor for mortality of diabetic patients worldwide [3, 4]. In addition to vascular complications, gastrointestinal (GI) symptoms such as gastroparesis, abdominal pain, diarrhoea, or constipation are also very common among diabetic patients. The relationship between these GI motility abnormalities and the presence of enteric neuropathy has been well documented in humans [5-7] as well as in rodent models $[8,9]$. We have also investigated for years the involvement of those nitrergic myenteric neurons in these GI complications which have a key role in regulating gut motility. According to our previous results, the nitrergic neurons located in different gut segments display different susceptibilities to diabetic damage and different levels of responsiveness to insulin treatment [9]. These results highlight the importance of the neuronal microenvironment along the GI tract in the pathogenesis of diabetic nitrergic neuropathy. Working towards a better understanding of the molecular differences in the neuronal microenvironment, we have demonstrated that the mesenterial capillaries [10] supplying the myenteric ganglia and 
the faeces-associated microbiota [11] are also serious targets of diabetic injuries in the same rat model. Diabetes-related microvascular complications and alterations in the composition of gut microbiota are also region specific in the different intestinal segments and are closely correlated with regiondependent nitrergic myenteric neuropathy.

It is well known that hyperglycaemia is clearly the culprit in the pathogenesis of diabetic complications, and there are convincing evidences that the onset of diabetes and its symptoms are closely associated with oxidative stress [12, 13]. Moreover, hyperglycaemia increases the formation of advanced glycation end products and inflammatory events $[14,15]$. There is also evidence that different subpopulations of myenteric neurons have selective responses to diabetic oxidative stress [16]. Besides an increased formation of reactive oxygen species (ROS), another main problem is the serious attenuation of antioxidant defense mechanisms. Among the endogenous antioxidants, the heme oxygenase (HO) system is recently emerging as an important player in diabetes and in GI inflammation [17-23]. HO is a microsomal enzyme with an essential role in heme catabolism producing biologically active carbon monoxide, biliverdin, and free iron $[21,24,25]$. Two main isoforms, $\mathrm{HO} 1$ and $\mathrm{HO} 2$, have been characterized as products of two different genes with distinct tissue- and cell-specific expression patterns [24, 26]. HO2 is considered to be a constitutive isozyme most highly expressed in neuronal tissues contributing to cell homeostasis, whereas HO1 is thought to be an inducible form with relatively low expression in most tissues [21, 24, 27]. Induction of the HO1 protein was shown to protect against a variety of stress conditions such as ischaemia [28], hypoxia [29], and ROS [30]. In addition, treatment with antioxidants minimizes or prevents the development of widespread complications in diabetic patients [31,32]. The induction of HO1 decreased ROS, rapidly restored neuronal nitric oxide synthase (nNOS) expression, and reversed diabetic gastroparesis in mice [33]. It has also been reported that induction of $\mathrm{HO} 1$ reduces glomerular injury and apoptosis in diabetic spontaneously hypertensive rats [34]. In streptozotocin(STZ-) induced diabetic rats, $\mathrm{HO} 1$ has been found to be induced in podocytes, protecting against apoptosis [35]. Moreover, in rat ileum, the antioxidant $\mathrm{HO} 2$ protects those NOS-containing neurons from oxidative stress in which it is colocalized [36]. Due to the beneficent effects of the HO system [23], these endogenous antioxidants can be the most important players in the prevention of oxidative injury and diabetic GI complications. However, HO induction may not always be beneficial: it can act also as a prooxidant mechanism depending on the disease milieu $[37,38]$, and the duration of $\mathrm{HO}$ stimulation may be a critical factor in triggering either the cytotoxic or the adaptive responses [39].

Based on earlier findings that as a result of the adequate oxidative environment in the proximal intestine, inducing a deep anaerobic state in the distal intestine [40, 41], the colon was more susceptible to damage by oxidative stress [42]; we supposed that the intestinal region-dependent colocalization of these endogenous antioxidants with nitrergic myenteric neurons results in different degrees of protection against chronic hyperglycaemia-induced oxidative stress. Therefore, our primary aim was to determine the gut segment-specific differences in the expression of the two $\mathrm{HO}$ isoforms, $\mathrm{HO} 1$ and $\mathrm{HO} 2$, and we also planned to evaluate the colocalization of these antioxidants with nNOS in myenteric neurons of different intestinal segments of chronic diabetic and control rats. To reflect the immediate alterations after the onset of hyperglycaemia, it was also our goal to study the serum level of HOs in some early stages of hyperglycaemia.

\section{Materials and Methods}

2.1. Animal Models. In all procedures involving experimental animals, the principles of laboratory animal care (NIH Publication No. 85-23, revised 1985) were strictly followed, and all the experiments were approved in advance by the Local Ethics Committee for Animal Research Studies at the University of Szeged. Adult male Wistar rats (Crl: WI BR; Toxi-Coop Zrt.), kept on standard laboratory chow (Farmer-Mix Kft., Zsámbék) and with free access to drinking water, were used throughout the experiments.

2.2. Acute Diabetic Rat Model. For the acute hyperglycaemic experiments, the rats (250-350 g) were divided randomly into four groups: STZ-induced 3-day diabetics $(n=5)$, 5day diabetics $(n=5), 10$-day diabetics $(n=5)$, and sex- and age-matched controls $(n=5)$. Hyperglycaemia was induced as described previously $[9,10]$. The animals were considered diabetic if the nonfasting blood glucose concentration was higher than $18 \mathrm{mM}$. The blood glucose level and weight of each animal were measured daily.

2.3. Chronic Diabetic Rat Model. For the chronic hyperglycaemic experiments, the rats (210-260g) were divided randomly into two groups: STZ-induced 10-week diabetics $(n=6)$ and sex- and age-matched controls $(n=5)$. Hyperglycaemia was induced as described previously $[9,10]$. The animals were considered diabetic if the nonfasting blood glucose concentration was higher than $18 \mathrm{mM}$. The blood glucose level and weight of each animal were measured weekly during the 10-week experimental period.

2.4. Blood Collection and Measurement of Serum HO1 and HO2 Concentrations of Acute and Chronic Diabetic Animals. The blood samples were collected from the tail vein of each animal (BD Vacutainer SST II Advance) after 3 days, 5 days, and 10 days as well as 10 weeks of STZ treatment. Then, they were centrifuged at $3200 \mathrm{rpm}$ for $10 \mathrm{~min}$ at room temperature, and the supernatants were stored in aliquots at $-80^{\circ} \mathrm{C}$ until use. The $\mathrm{HO} 1$ and $\mathrm{HO} 2$ levels of the serum samples of acute and chronic diabetic animals were determined by means of quantitative ELISA according to the manufacturer's instructions (SunRed Biotechnology, Shanghai, China). Optical density was measured at $450 \mathrm{~nm}$ (Benchmark Microplate Reader; Bio-Rad, Budapest, Hungary). The serum $\mathrm{HO} 1$ and $\mathrm{HO} 2$ concentrations were expressed as $\mathrm{ng} / \mathrm{ml}$.

2.5. Tissue Handling. Ten weeks after the onset of hyperglycaemia, the animals of the chronic diabetic experiment were killed by cervical dislocation under chloral hydrate anaesthesia (375 mg/kg ip). The gut segments of the control and STZ- 
induced diabetic rats were dissected and rinsed in $0.05 \mathrm{M}$ phosphate buffer (PB; pH 7.4). Samples were taken from the duodenum ( $1 \mathrm{~cm}$ distal to the pylorus), the ileum $(1 \mathrm{~cm}$ proximal to the ileocaecal junction), and the proximal colon and processed for immunohistochemical studies and enzymelinked immunosorbent assays (ELISA). For double-labelling immunohistochemistry, the intestinal segments were cut along the mesentery, pinched flat, and fixed overnight at $4^{\circ} \mathrm{C}$ in $4 \%$ paraformaldehyde solution buffered with $0.1 \mathrm{M}$ $\mathrm{PB}$ ( $\mathrm{pH}$ 7.4). The samples were then washed, the mucosa, submucosa, and circular smooth muscle were removed, and whole-mounts with the myenteric plexus adhering to the longitudinal muscle were prepared. For the ELISA, the gut segments were cut along the mesentery and pinched flat. The layer of mucosa and submucosa was removed, and the residual material was snap frozen in liquid nitrogen and stored at $-80^{\circ} \mathrm{C}$ until use.

2.6. Double-Labelling Fluorescent Immunohistochemistry. For double-labelling immunohistochemistry, whole-mount preparations derived from different gut segments were immunostained with nNOS and $\mathrm{HO} 1$ or HO2. Briefly, after blocking of the preparations in PB containing $0.1 \%$ bovine serum albumin, $10 \%$ normal goat serum, and $0.3 \%$ Triton X-100, they were incubated overnight with anti-nNOS (rabbit; Cayman Chemical, Ann Arbor, MI, USA; final dilution $1: 200$ ) and anti-HO1 (mouse; Novus Biologicals Europe, Abington, UK; final dilution 1:200) or anti-HO2 (mouse; Santa Cruz Biotechnology, Inc., Dallas, Texas, USA; final dilution 1:50) primary antibodies. After washing in $\mathrm{PB}$, whole-mounts were incubated with antirabbit Alexa Fluor 488 (Life Technologies Corporation, Molecular Probes, Inc., Eugene, OR; final dilution 1:200) and antimouse $\mathrm{Cy}^{\mathrm{TM}} 3$ (Jackson ImmunoResearch Laboratories Inc., Baltimore Pike, PA; final dilution 1:200) secondary antibodies for 4 hours. All incubations were carried out at room temperature. Negative controls were performed by omitting the primary antibody, when no immunoreactivity was observed. Whole-mounts were mounted on slides in EverBrite $^{\mathrm{TM}}$ Mounting Medium (Biotium, Inc., Hayward, CA), observed and photographed with an Olympus BX51 fluorescent microscope equipped with an Olympus DP70 camera. Fifty myenteric ganglia were taken from each intestinal segment from each experimental group, and the numbers of nNOS-IR, HO1- or HO2-IR neurons, and those myenteric neurons in which the two markers were colocalized (per ganglia) were counted. The percentage of ganglia containing HO-IR or nNOS-HO-IR neurons or none of these was also determined.

\subsection{Measurement of Tissue HO1 and HO2 Concentrations.} The intestinal tissue samples were frozen in liquid nitrogen, crushed into powder in a mortar, and homogenized in $500 \mu \mathrm{l}$ homogenizing buffer (100 $\mu \mathrm{l}$ Protease Inhibitor Cocktail [Sigma-Aldrich, St. Louis, MO] in $20 \mathrm{ml} 0.05 \mathrm{M} \mathrm{PB}$ ). Tissue homogenates were centrifuged at $5000 \mathrm{rpm}$ for $20 \mathrm{~min}$ at $4^{\circ} \mathrm{C}$. The $\mathrm{HO} 1$ and $\mathrm{HO} 2$ levels of the intestinal tissue samples were determined by means of quantitative ELISA according to the manufacturer's instructions (SunRed Biotechnology,
Shanghai, China). Optical density was measured at $450 \mathrm{~nm}$ (Benchmark Microplate Reader; Bio-Rad, Budapest, Hungary). The tissue $\mathrm{HO} 1$ and $\mathrm{HO} 2$ concentrations were expressed as $\mathrm{ng} / \mathrm{mg}$ protein.

2.8. Bradford Protein Micromethod for the Determination of Tissue Protein Content. For the determination of protein content of tissue samples, a commercial protein assay kit was used. Bradford reagent was added to each sample. After mixing and following $10 \mathrm{~min}$ incubation, the samples were assayed spectrophotometrically at $595 \mathrm{~nm}$. Protein level was expressed as $\mathrm{mg}$ protein $/ \mathrm{ml}$.

2.9. Statistical Analysis. Statistical analysis was performed with one-way ANOVA and the Newman-Keuls test. All analyses were carried out with GraphPad Prism 6.0 (GraphPad Software, La Jolla, CA, USA). A probability of $P<0.05$ was set as the level of significance. All data were expressed as means \pm SEM.

\section{Results}

3.1. Disease Characteristics in Diabetic Rats. The general characteristics of the control and STZ-treated animals from the acute and chronic diabetic experiments 3 days, 5 days, 10 days, and ten weeks after the STZ treatment are shown in Tables 1 and 2. The chronic diabetic rats were characterized by a significantly reduced body weight and an increased blood glucose concentration $(23.31 \pm 0.53 \mathrm{mM})$ as compared to the age- and sex-matched controls.

3.2. Serum Level of HOs in Acute and Chronic Diabetic Animals. In the serum samples, the $\mathrm{HO} 1$ expressed at higher level than the $\mathrm{HO} 2(7.3 \pm 0.32$ versus $4.19 \pm 0.19 \mathrm{ng} / \mathrm{ml})$ in the healthy animals of acute study (Figures 1(a) and 1(c)). Three days after the STZ treatment, the HO1 expression increased significantly $(P<0.01)$ as compared to controls, following a recovery in the 5-day-diabetic rats. Moreover, it decreased further in the 10-day diabetics as compared to control animals (Figure 1(a)). The expression of $\mathrm{HO} 1$ was also decreased in the diabetic rats of the chronic study as compared to controls; furthermore, the serum $\mathrm{HO} 1$ concentration was not significantly different in 10-week and 10-day diabetics (5.9 \pm 1.09 versus $5.48 \pm$ $0.3 \mathrm{ng} / \mathrm{ml}$; Figures 1(a) and 1(b)).

In the case of $\mathrm{HO} 2$, similar changes were detected in the serum samples of acute and chronic study. Briefly, the $\mathrm{HO} 2$ level was significantly decreased in 5-day-, 10-day-, and 10-week-diabetic animals as compared to their controls (Figures 1(c) and 1(d)).

3.3. Evaluation of Myenteric Ganglia Representing HO-IR and $n N O S-H O-I R$ Neurons. Nitrergic myenteric neurons were labelled by nNOS immunohistochemistry, whereas HOrepresenting neurons were visualized by $\mathrm{HO} 1$ and $\mathrm{HO} 2$ immunohistochemistry. The densities of $\mathrm{HO} 1-$ and $\mathrm{HO}_{2}-$ IR- as well as $\mathrm{HO} 1$ - and $\mathrm{HO} 2$-representing nitrergic neurons were evaluated per ganglia of the duodenum, ileum, and colon in control and diabetic rats (Figures 2 and 3). 
TABLE 1: Weight and glycaemic characteristics of the animal groups of the acute diabetic experiment.

\begin{tabular}{|c|c|c|c|c|}
\hline & \multicolumn{2}{|c|}{ Body weight $(\mathrm{g}) \pm$ SEM } & \multicolumn{2}{|c|}{ Blood glucose concentration $(\mathrm{mM}) \pm \mathrm{SEM}$} \\
\hline & Initial & Final & Initial & Final (average) \\
\hline Controls $(n=5)$ & $303.8 \pm 9.46$ & $339.5 \pm 14.97$ & $5.53 \pm 0.24$ & $5.63 \pm 0.27$ \\
\hline 3-day diabetics $(n=5)$ & $273.0 \pm 11.15$ & $274.3 \pm 8.09$ & $6.17 \pm 0.37$ & $23.03 \pm 2.63^{* * * *}$ \\
\hline 5 -day diabetics $(n=5)$ & $293 \pm 13.7$ & $301.7 \pm 11.63$ & $5.87 \pm 0.29$ & $23.14 \pm 2.01^{* * * *}$ \\
\hline 10-day diabetics $(n=5)$ & $310.5 \pm 4.27$ & $346 \pm 9.06$ & $4.9 \pm 0.29$ & $23.95 \pm 1.18^{* * * *}$ \\
\hline
\end{tabular}

${ }^{* * * *} P<0.0001$ (initial versus final)

TABle 2: Weight and glycaemic characteristics of the animal groups of the chronic diabetic experiment.

\begin{tabular}{|c|c|c|c|c|}
\hline & \multicolumn{2}{|c|}{ Body weight $(\mathrm{g}) \pm \mathrm{SEM}$} & \multicolumn{2}{|c|}{ Blood glucose concentration $(\mathrm{mM}) \pm \mathrm{SEM}$} \\
\hline & Initial & Final & Initial & Final (average) \\
\hline Controls $(n=5)$ & $232.2 \pm 7.29$ & $486 \pm 4.93^{* * * *}$ & $7.08 \pm 0.22$ & $6.3 \pm 0.13$ \\
\hline STZ-treated diabetics $(n=6)$ & $235.3 \pm 10.48$ & $382.7 \pm 3.53^{* * * * \text { oooo }}$ & $6.6 \pm 0.1$ & $23.31 \pm 0.53^{* * * * \text { oooo }}$ \\
\hline
\end{tabular}

${ }^{* * * *} P<0.0001$ (initial versus final), ${ }^{0000} P<0.0001$ (between final values).

The proportion of $\mathrm{HO} 1$-including myenteric ganglia was different in the various intestinal segments in control and diabetic rats. They were observed in the highest percentage in the colon (94\%) and in the duodenum (88\%) of controls. However, only half of the ileal ganglia contained HO1-IR neurons and from these ganglia only $16 \%$ represented nNOS-HO1 colocalized neurons in the control rats (Figures 4(a) and 4(c)).

In the diabetic group, all of the ileal ganglia included HO1-IR neurons, and more than $60 \%$ of them also represented double-stained neurons. In the diabetic colon, all of the myenteric ganglia included HO1-IR and also doublestained neurons (100\% versus $78 \%$ in controls), whereas in the diabetic duodenum, the percentage of ganglia containing HO1- and nNOS-HO1-IR neurons was slightly decreased ( $88 \%$ versus $73 \%$ and $72 \%$ versus $61 \%$ in controls, resp.) (Figures 4(a) and 4(c)).

The proportion of ganglia representing $\mathrm{HO} 2$ - and nNOS$\mathrm{HO} 2-\mathrm{IR}$ neurons also varied in a region-dependent way. In controls, $70-80 \%$ of the ganglia included HO2-IR neurons in all gut segments with increased rate in diabetic animals (Figure $4(\mathrm{~b})$ ). The lowest proportion of nNOS-HO2representing ganglia was observed in the ileum $(27 \%)$ and the highest in the colon $(80 \%)$ of the control rats. In the diabetic group, the rate of nNOS-HO2-including ganglia increased in all intestinal segments; however, the greatest, 3-fold increase was observed in the ileum (Figure 4(d)).

3.4. Total Number of HO1-IR- and HO1-Representing Nitrergic Neurons. The presence of HO1-IR neurons varied distinctly in the different gut segments even in the control animals. The least HO1-IR cells were counted in the ileal ganglia $(1.44 \pm 0.31)$, whereas 4 -fold more HO1-IR neurons were observed in the duodenum $(6.04 \pm 0.59)$ and 7 -fold more in the myenteric ganglia of the colon $(10.08 \pm 1.05)$. Except for the duodenum, the total number of HO1-IR neurons displayed a robust increase in the ileum $(P<0.0001)$ and colon $(P<0.0001)$ of diabetic rats as compared to the control data. The largest increase was observed in the ileum, where almost 7-fold more HO1-IR neurons were counted in the diabetics relative to controls $(9.62 \pm 0.95$ versus $1.44 \pm 0.31)$ (Figure 5(a)).

The number of nNOS-HO1-IR myenteric neurons showed a very similar distribution in the control group with the lowest value in the ileal and the highest in the colonic ganglia. Moreover, the number of nNOS-HO1 colocalized neurons was also elevated 7-fold in the ileum of diabetics as compared to controls $(1.41 \pm 0.27$ versus $0.2 \pm 0.07)$. In the diabetic colon, the number of nNOS-HO1 colocalized neurons was more than doubled, whereas in the duodenum of diabetic rats it remained unchanged (Figure 5(b)). Since the number of total HO1-IR and also that of the nNOS-HO1IR neurons represented similar alterations in the different gut segments of control and diabetic rats, therefore the proportion of HO1-IR neurons colocalizing with nNOS did not change in any of the different intestinal regions. In the ileum, only $18 \%$ of HO1-IR neurons were colocalized with nNOS, whereas this ratio was around $30 \%$ in the ganglia of the duodenum and colon under both experimental conditions (Figure 5(c)).

Although the total number of nNOS-IR neurons decreased in all intestinal segments $(9 \pm 0.39$ versus $7.53 \pm 0.29$ in the duodenum, $P<0.01 ; 6.32 \pm 0.35$ versus $5.78 \pm 0.27$ in the ileum; $9.5 \pm 0.48$ versus $7.38 \pm 0.42$ in the colon, $P<0.001$ ), the proportion of nNOS-IR neurons colocalizing with HO1 exhibited a nearly 8-fold increase in the ileum and a 3 -fold increase in the colon of diabetics. This ratio was barely $3 \%$ in the ileum and $23 \%$ in the colon of the control rats, whereas it was $24 \%$ and $72 \%$ in the diabetics, respectively (Figure $5(\mathrm{~d})$ ).

3.5. Total Number of HO2-IR- and HO2-Representing Nitrergic Neurons. The distribution of HO2-IR neurons also displayed a region-dependent pattern in the control rats. The bulk of the HO2-IR neurons was located in the colonic ganglia (13.96 \pm 1.73$)$, whereas less than half as many were 


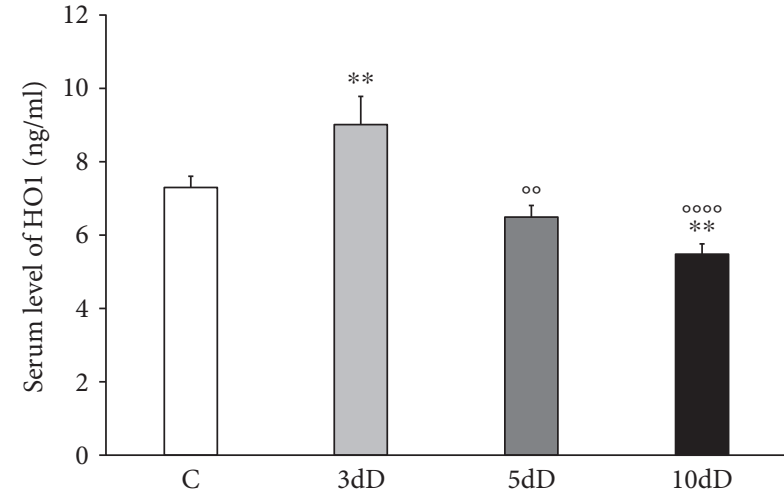

(a)

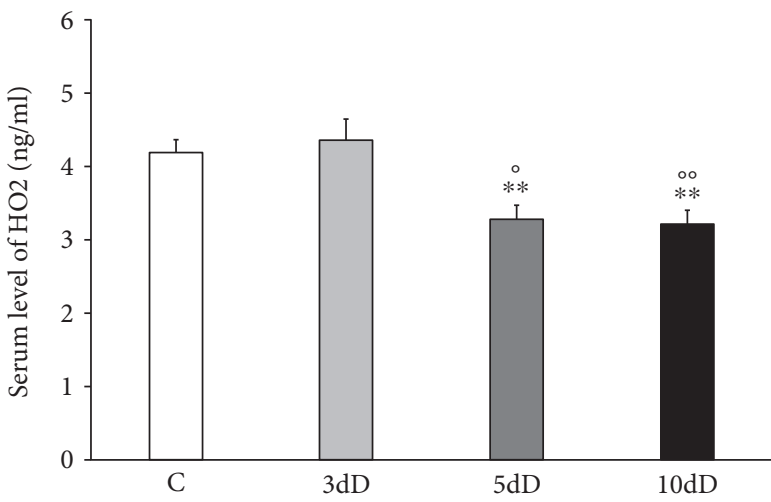

(c)

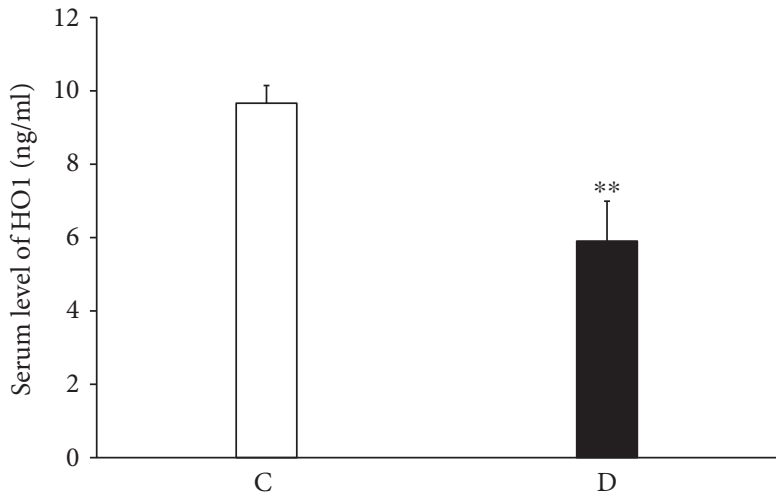

(b)

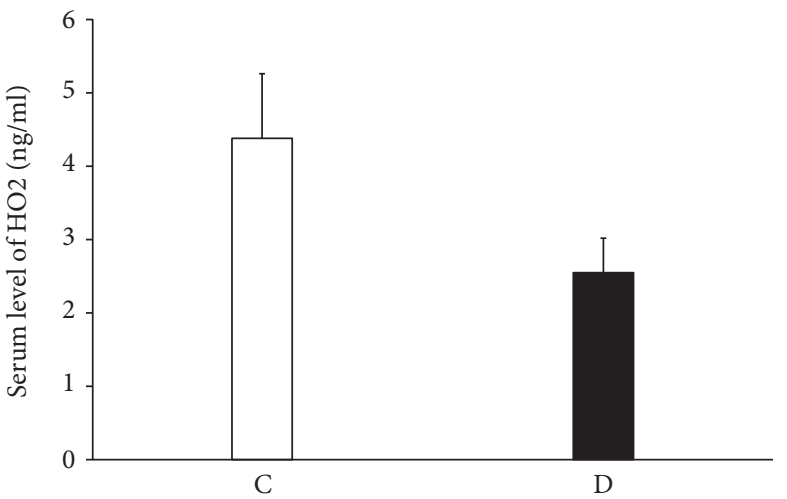

(d)

FIgUre 1: The serum level of HO1 and HO2 in acute (a, c) and chronic (b, d) diabetic rats. The HO1 expression increased significantly in the 3 -day diabetics with a recovery in the 5-day-diabetic rats, and it decreased further in the 10-day-diabetic animals as compared to the controls (a). The serum HO1 level was almost the same in the 10-week and the 10-day diabetics (a, b). The serum concentration of HO2 was also decreased in 5-day-, 10-day-, and 10-week-diabetic animals as compared to their controls (c, d). Data are expressed as means \pm SEM. ${ }^{* *} P<0.01$ (compared to the controls), ${ }^{\circ} P<0.05$; ${ }^{\circ o} P<0.01$; ${ }^{\circ 00 o} P<0.0001$ (compared to the 3 -day diabetics). C: controls; 3dD: 3-day diabetics; 5dD: 5-day diabetics; 10dD: 10-day diabetics; D: 10-week diabetics.

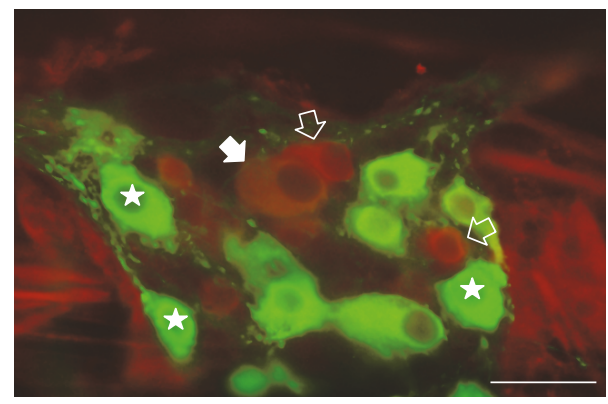

FIGURE 2: Representative fluorescent micrograph of a whole-mount preparation of myenteric ganglia from the colon of a diabetic rat after nNOS-HO1 immunohistochemistry. Stars indicate neurons that labelled for nNOS only, open arrows show neurons that labelled for $\mathrm{HO} 1$ only, and the solid arrow points to a myenteric neuron that double-labelled for both $\mathrm{nNOS}$ and HO1. Scale bar: $50 \mu \mathrm{m}$.

counted in the myenteric ganglia of the ileum and the duodenum. In the diabetic rats, the total number of HO2-IR neurons increased in the different gut segments; however, the increase was significant only in the ileum $(P<0.01)$, where

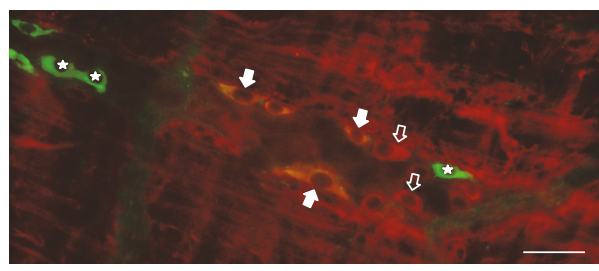

FIGURE 3: Representative fluorescent micrograph of a whole-mount preparation of myenteric ganglia from the duodenum of a diabetic rat after nNOS-HO2 immunohistochemistry. Stars indicate neurons that labelled for nNOS only, open arrows show neurons that labelled for $\mathrm{HO} 2$ only, and solid arrows point to myenteric neurons that double-labelled for both nNOS and HO2. Scale bar: $50 \mu \mathrm{m}$.

the HO2-IR neuronal number was doubled relative to controls $(11.94 \pm 1.24$ versus $5.85 \pm 0.85)$ (Figure 6(a)). The number of nNOS-HO2-IR myenteric neurons represented similar expression in controls, where the majority of the colocalized neurons also occurred in the ganglia of the colon $(4.32 \pm 0.64)$, whereas an average of $0-1$ cells was found in the ileal and duodenal ganglia. Moreover, the number of 


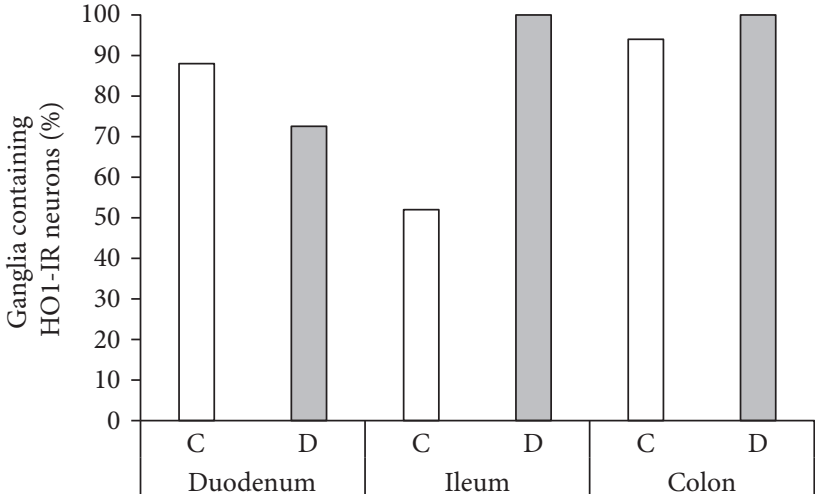

(a)

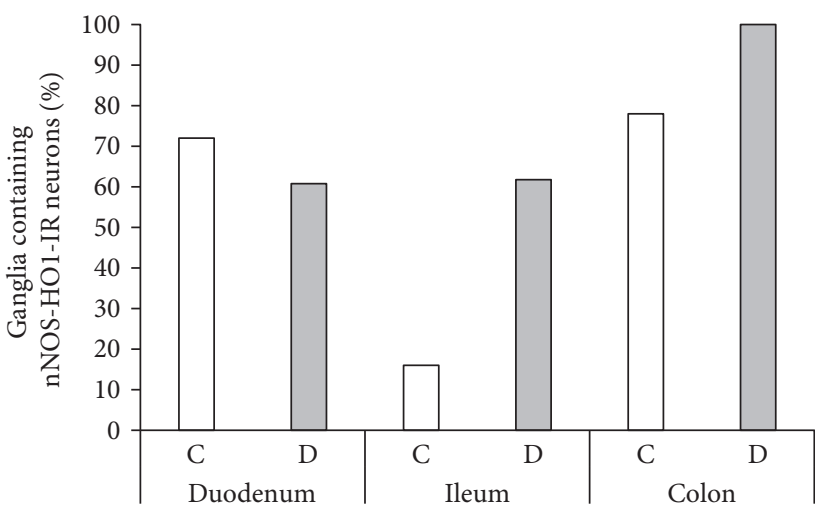

(c)

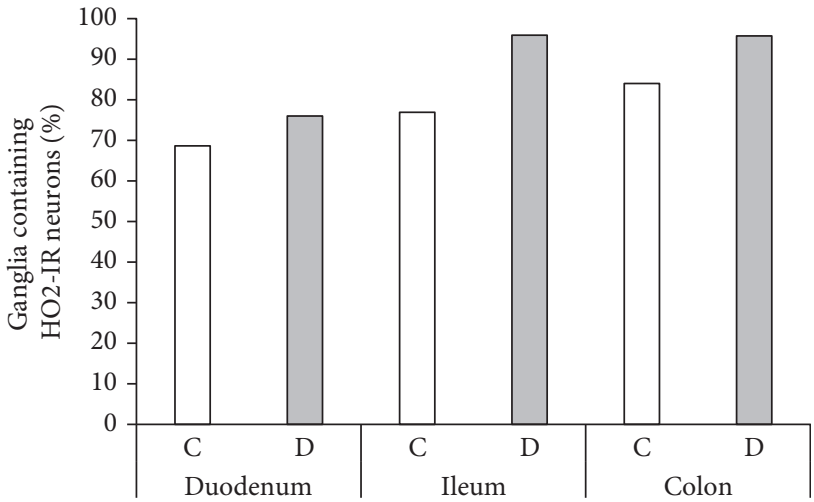

(b)

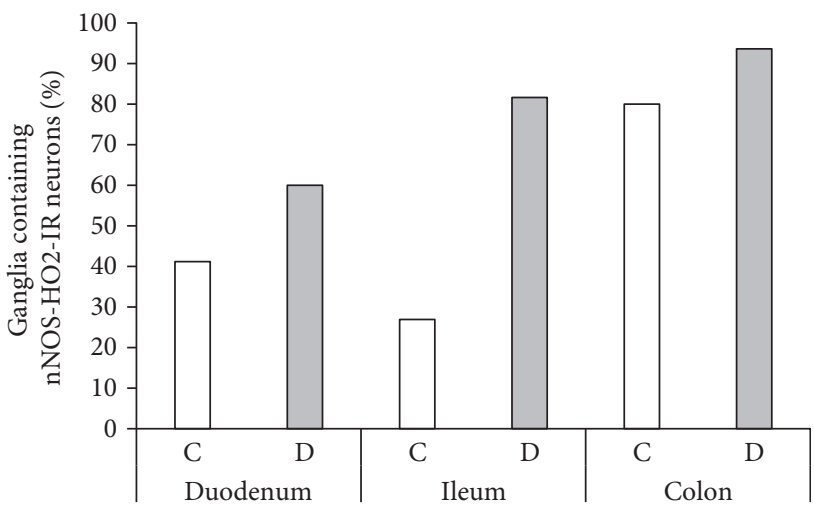

(d)

FIgure 4: Percentage of myenteric ganglia containing HO1-IR (a), HO2-IR (b), nNOS-HO1-IR (c), and nNOS-HO2-IR (d) neurons. Only half of the ileal ganglia contained HO1-IR neurons, and from these only $16 \%$ of the ganglia represented double-stained neurons in the control rats. In the diabetic group, all of the ileal and colonic ganglia included HO1-IR neurons, and from these more than $60 \%$ of ileal and $100 \%$ of colonic ganglia also represented the double-stained neurons. More than $70 \%$ of ganglia represented HO2-IR neurons under both experimental conditions, and a large increase in the proportion of ganglia containing double-stained neurons was revealed in diabetic state. C: controls; D: diabetics.

nNOS-HO2 colocalized neurons was also elevated more than 6 -fold in the ileum of diabetics as compared to controls (2.65 \pm 0.34 versus $0.42 \pm 0.11 ; P<0.001$ ) (Figure $6(\mathrm{~b})$ ). Since the number of total HO2-IR and also that of the nNOS-HO2IR neurons did not alter significantly in the duodenum and colon of control and diabetic rats, therefore the proportion of HO2-IR neurons colocalizing with nNOS remained unchanged in these intestinal regions. In the duodenum $28-30 \%$, whereas in the colon $33-39 \%$ of HO2-IR neurons were colocalized with nNOS under both experimental conditions. However, this proportion was $6 \%$ in the ileum of the control rats with a pronounced increase in the same segment of diabetics $(24 \% ; P<0.001)$ (Figure 6(c)).

Although the total number of nNOS-IR neurons decreased in all intestinal regions $(10.39 \pm 0.51$ versus $7.96 \pm 0.44$ in the duodenum, $P<0.01 ; 7.33 \pm 0.42$ versus $6.23 \pm 0.22$ in the ileum, $P<0.05 ; 10.48 \pm 0.69$ versus $8.08 \pm$ 0.69 in the colon, $P<0.01$ ), however, the proportion of nNOS-IR neurons colocalizing with $\mathrm{HO} 2$ was definitely increased in all gut segments of the diabetic group. The largest, nearly a 7 -fold increase, in this ratio was observed in the ileum (40\% versus 6\%), but significant increases were also shown in the duodenum ( $22 \%$ versus $9 \%$ ) and the colon
(68\% versus $44 \%$ ) of diabetics as compared to controls (Figure 6(d)).

3.6. Tissue Level of HOs. In the tissue homogenates including the smooth muscle layers of the intestinal wall and the myenteric plexus, the expressional patterns of $\mathrm{HO} 1$ and $\mathrm{HO} 2$ were strictly region dependent in the healthy animals of chronic study. The highest concentrations of $\mathrm{HO}$ enzymes were detected in the tissue homogenates of the control duodenum with $46.35 \pm 3.22 \mathrm{ng} / \mathrm{mg}$ protein in the case of $\mathrm{HO} 1$ and $42.72 \pm 3.53 \mathrm{ng} / \mathrm{mg}$ protein in the case of $\mathrm{HO} 2$ (Figures 7(a) and 7(b)). In the ileum and colon of controls, the tissue level of HOs was significantly lower than in the duodenum. In the 10-week diabetics, the duodenum was the only gut segment where the tissue levels of HOs decreased strongly $(24.35 \pm 1.12 \mathrm{ng} / \mathrm{mg}$ protein in the case of $\mathrm{HO} 1$ and $28.44 \pm 0.97 \mathrm{ng} / \mathrm{mg}$ protein in the case of $\mathrm{HO} 2$ ), whereas they remained unchanged in the ileum and colon (Figures 7(a) and 7(b)).

Since the changes in the total number of HO-IR- and $\mathrm{HO}$-representing nitrergic neurons was the most elevated in the ileum of 10-week-diabetic rats, therefore we chose this particular gut segment also from the acute study to 


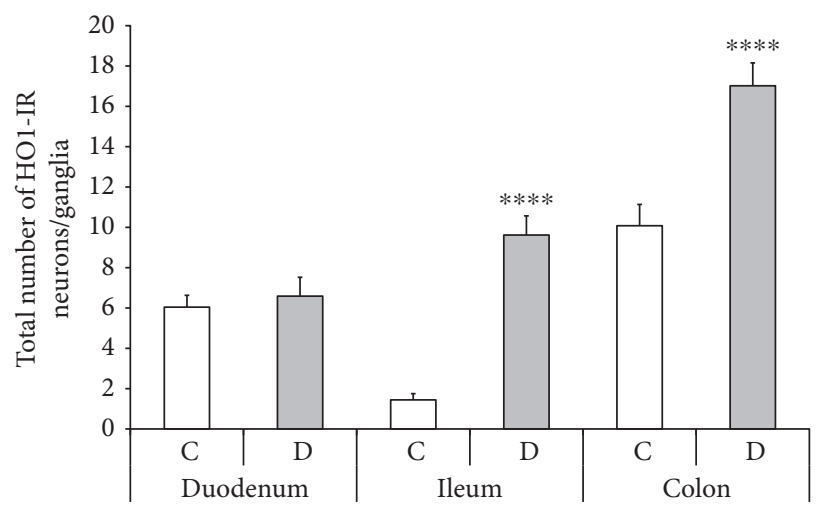

(a)

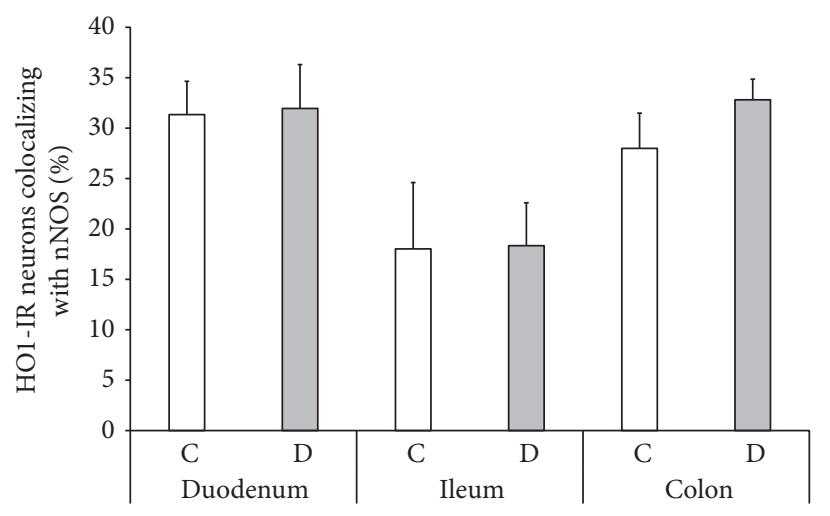

(c)

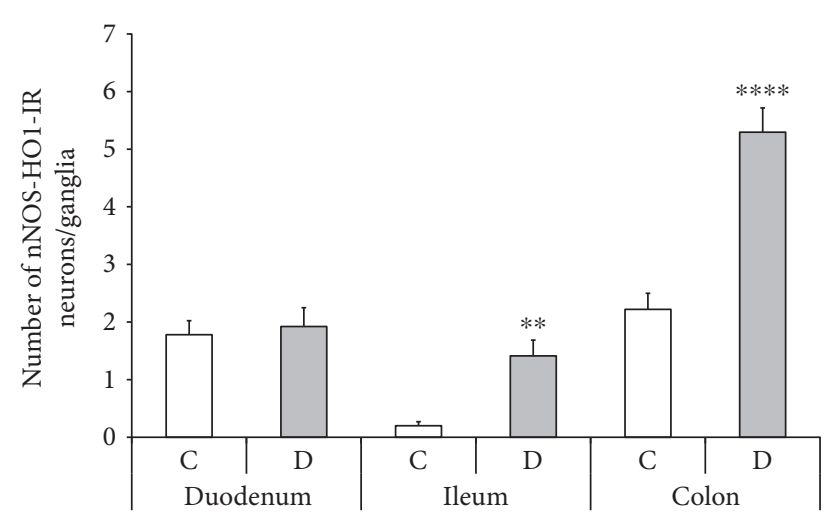

(b)

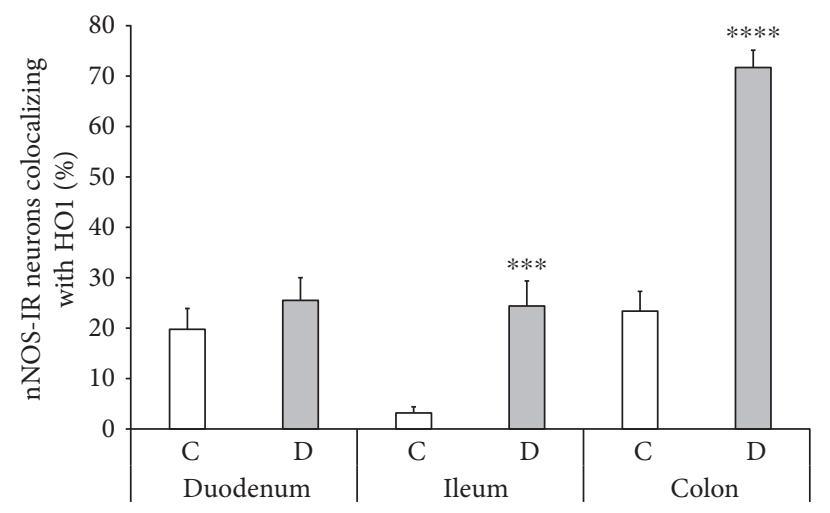

(d)

FIGURE 5: Quantitative evaluation of the total number of HO1-IR neurons (a), the number of nNOS-HO1-IR neurons (b), the proportion of HO1-IR neurons colocalizing with nNOS (c), and the proportion of nNOS-IR neurons colocalizing with HO1 (d) in the myenteric ganglia of the duodenum, ileum, and colon of control and diabetic rats. Except for the duodenum, the total number of HO1-IR neurons and the number of nNOS-HO1-IR myenteric neurons displayed a robust increase in the ileum and colon of diabetic rats. The percentage of HO1-IR neurons colocalizing with nNOS did not change in the different intestinal segments. However, the proportion of nNOS-IR neurons colocalizing with HO1 exhibited a nearly 8 -fold increase in the ileum and a more than 2-fold increase in the colon of diabetics. Data are expressed as means \pm SEM. ${ }^{* *} P<0.01,{ }^{* * *} P<0.001$, and ${ }^{* * * *} P<0.0001$ (between controls and diabetics). C: controls; D: diabetics.

measure the tissue level of HOs. In the tissue homogenates of the ileum, the $\mathrm{HO} 2$ expressed at higher level than the HO1 (26.94 \pm 0.81 versus $20.55 \pm 1.49 \mathrm{ng} / \mathrm{mg}$ protein) in the healthy animals of the acute study. The acute hyperglycaemia did influence neither the $\mathrm{HO} 1$ nor the $\mathrm{HO} 2$ expression 3, 5, or 10 days after the STZ treatment as compared to controls $(19.35 \pm 0.98$ versus $18.09 \pm 0.77$ versus $18.76 \pm 1.23 \mathrm{ng} / \mathrm{mg}$ protein in the case of $\mathrm{HO} 1$ and $27.76 \pm 0.92$ versus $28.66 \pm 1.02$ versus $27.72 \pm 1.31 \mathrm{ng} / \mathrm{mg}$ protein in the case of $\mathrm{HO} 2$, resp.).

\section{Discussion}

Based on our findings of immediate alterations after the onset of hyperglycaemia, we presume that the increased HO1 level in the serum of 3-day-diabetic rats can be a result of the stress response caused by STZ treatment. This acute HO response does not appear in the intestinal tissue homogenates (at least in the ileum), which further strengthens our presumption. This acute stress response appeared firstly in the systemic circulation and not in the tissue of the gut and then it declines gradually here in the 5- and 10-day-diabetic rats. Moreover, the serum concentration of $\mathrm{HO} 1$ and $\mathrm{HO} 2$ were almost the same in 10-day- and 10-week-diabetic animals.

In support of our earlier finding that the susceptibility of nitrergic myenteric neurons to experimentally induced diabetes is strictly regional [9], the present study provides evidence of gut segment-specific diabetes-related induction of the endogenous $\mathrm{HO}$ system and also the intestinal region-dependent enhanced colocalization of $\mathrm{HO} 1$ and $\mathrm{HO} 2$ with nNOS in myenteric neurons.

The occurrence of $\mathrm{HO} 1$ - or $\mathrm{HO} 2$-containing myenteric ganglia, furthermore the presence of those ganglia which include nNOS-HO1 or nNOS-HO2 colocalized neurons, was the most pronounced in the colon and the slightest in the ileum of the control rats. Similarly, the number of HO1- or HO2-IR and nNOS-HO1 or nNOS-HO2-IR neurons was the highest in the colon and the lowest in the ileum under control conditions. Interestingly, in the duodenum of controls, although the number of HO1-IR or HO2-IR and nNOS-HO1-IR or nNOS-HO2-IR neurons was less than in the colon, still the presence of either HO-IR or nNOS-HOIR neurons representing myenteric ganglia was nearly as explicit as in the colon. 


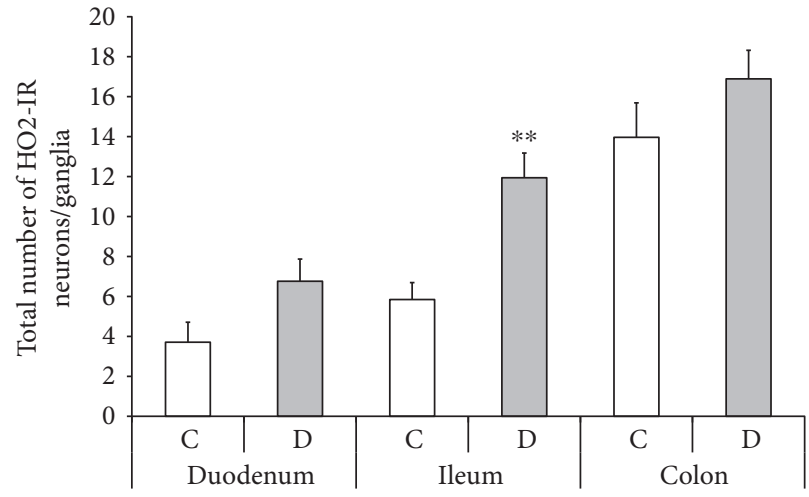

(a)

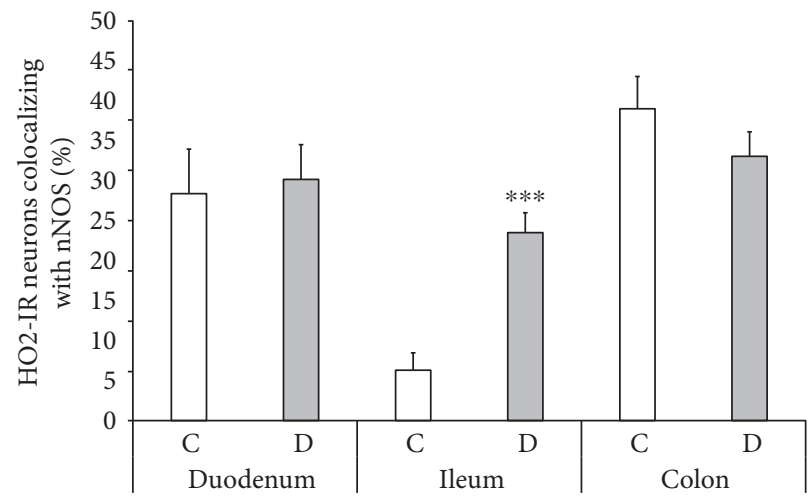

(c)

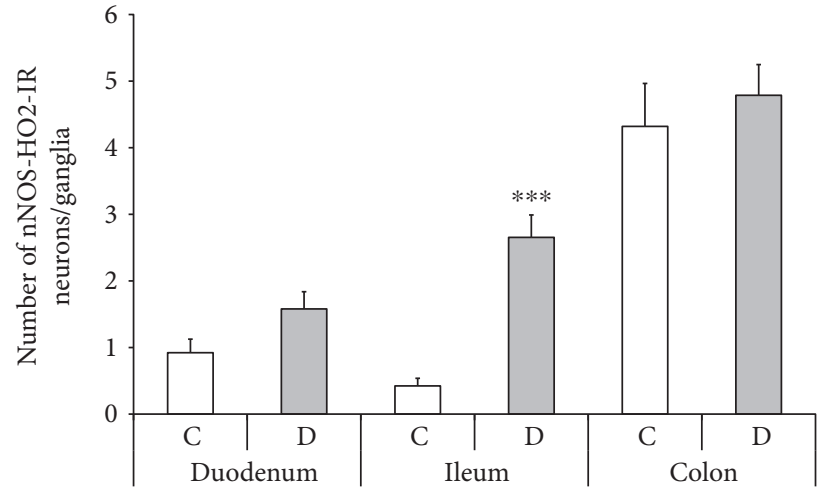

(b)

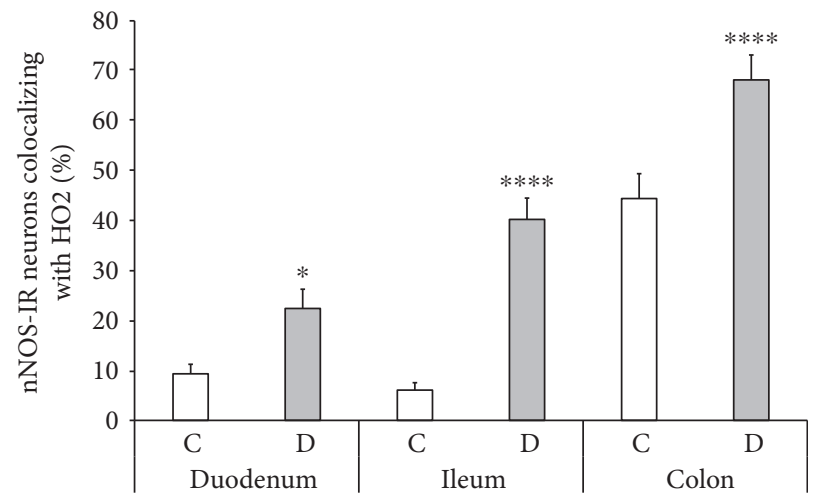

(d)

FIGURE 6: Quantitative evaluation of the total number of HO2-IR neurons (a), the number of nNOS-HO2-IR neurons (b), the proportion of $\mathrm{HO} 2-\mathrm{IR}$ neurons colocalizing with nNOS (c), and the proportion of nNOS-IR neurons colocalizing with $\mathrm{HO} 2$ (d) in the myenteric ganglia of the duodenum, ileum, and colon of control and diabetic rats. The total number of HO2-IR neurons and the number of nNOS-HO2-IR myenteric neurons largely increased in the ileum of diabetic rats. The percentage of HO2-IR neurons colocalizing with nNOS was elevated only in the diabetic ileum. However, the proportion of nNOS-IR neurons colocalizing with $\mathrm{HO} 2$ was enhanced in each gut segment of diabetics. The largest increase, more than 6-fold, was observed in the ileal ganglia. Data are expressed as means \pm SEM. ${ }^{*} P<0.05,{ }^{* *} P<0.01,{ }^{* * *} P<0.001$, and ${ }^{* * * *} P<0.0001$ (between controls and diabetics). C: controls; D: diabetics.

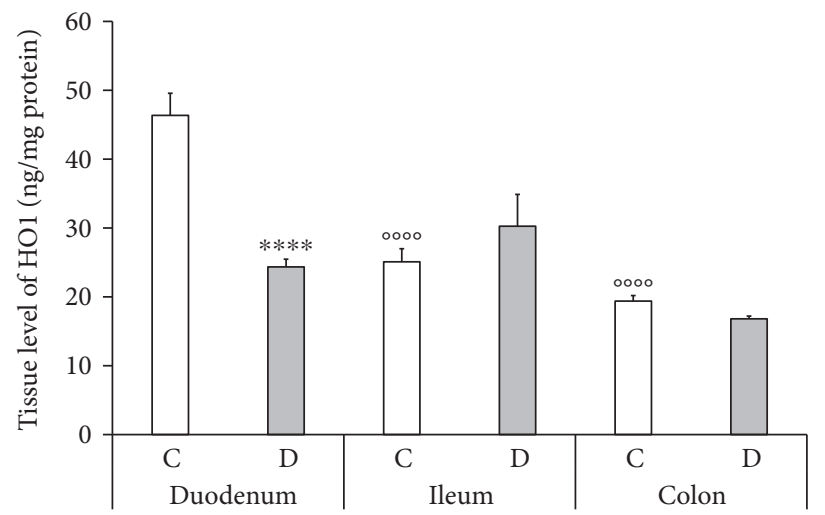

(a)

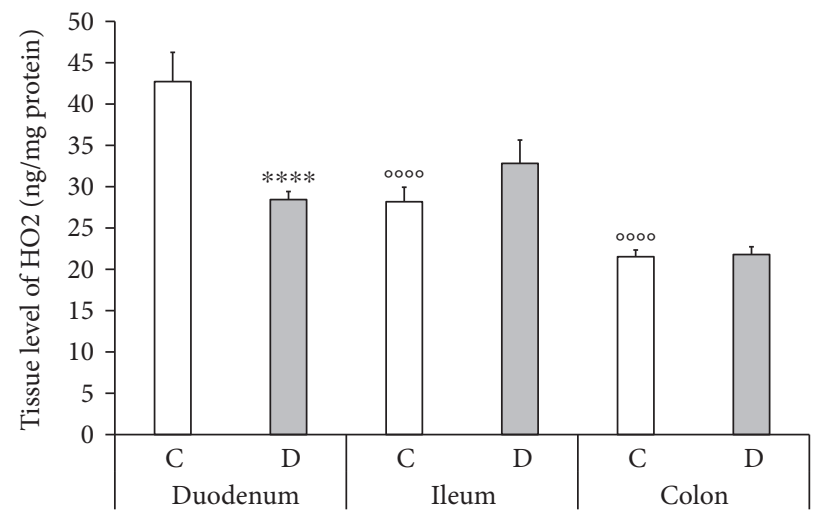

(b)

Figure 7: The tissue level of HO1 (a) and HO2 (b) in the different gut segments of control and diabetic rats. The levels of HO1 and HO2 were the highest in the tissue homogenates from the duodenum of controls and decreased to the distal part of the GI tract. In the diabetic rats, a statistically intense decrease was observed in the level of $\mathrm{HO} 1$ and $\mathrm{HO} 2$ in the tissue homogenates of the duodenum but not in those of the ileum and colon. Data are expressed as means \pm SEM. ${ }^{* * *} P<0.0001$ (between controls and diabetics), ${ }^{\text {oooo }} P<0.0001$ (between different gut segments of controls). C: controls; D: diabetics. 
Even under physiological conditions, these gut segmentspecific differences raise the question of why the myenteric ganglia and nitrergic neurons are distributed differently, depending on their intestinal location. It is well established that the anatomical, functional, and pathological regionality of the GI tract develops under strict genetic control $[43,44]$, which in itself can be responsible for the unique features of the enteric neurons in a healthy state and for their different susceptibilities to pathological insults in different gut segments. Emerging evidences $[45,46]$ confirm that the different degrees of susceptibility of enteric neurons to a pathological stimulus such as hyperglycaemia might be related to the prevalence of bacteria in the different parts of the GI tract, which among others give rise to major differences in the intestinal redox status and the oxygen supply of the small and large intestine [47-49]. The microflora of facultative bacteria expands during infancy and creates a reducing environment that supports the population of the gut by anaerobic strains, inducing a deep anaerobic state in the distal intestine. The prooxidant environment of the colon as compared to the small intestine may also contribute to greater cancer susceptibility [48]. In our recent study [13], we already demonstrated evidence of gut region-specific accumulation of reactive oxygen species and also that enhanced oxidative stress leads to regionally distinct activation of antioxidant and apoptotic marker molecules in proximal and distal part of the gut in rats with STZ-induced diabetes. There was no significant change in peroxynitrite level in the duodenum in any of the examined groups. However, in the diabetic colon, the peroxynitrite level was significantly increased, and the presence of severe necrosis was also confirmed by electron microscopy [13]. These data also suggest that the distal part of the gut is more vulnerable than the proximal to oxidative stress.

Therefore, we suppose that in the colon, where the baseline oxidative environment is far from optimal, the basal expression of HOs as essential players of the endogenous defense mechanisms is the most pronounced. In another study by Battish et al. [50], region-specific coexistence of $\mathrm{HO} 2$ with nNOS was also observed in the opossum anorectum, where the high percentage of colocalization in the myenteric plexus fell from almost $100 \%$ in the internal anal sphincter to $56 \%$ proximally in the rectum. This supports our findings that $44 \%$ of nNOS-IR neurons are also colocalized with $\mathrm{HO} 2$ in the colon of the control rats.

We also suggest that in the ileum the presence of the $\mathrm{HO}$ proteins is extremely low in controls, which may result in much lower protection against different pathological stimuli. Other groups have also demonstrated a hardly detectable expression of $\mathrm{HO} 1$ protein in mucosal epithelial cells of the ileum, and these were much more vulnerable to injuries by haemorrhagic shock [51] or septic damage [52]. Miller et al. [53] detected little if any immunoreactivity of $\mathrm{HO} 1$ in the human antrum and jejunum. However, Donat et al. [54] reported that only $10 \%$ of $\mathrm{HO} 2$-positive neurons contained NOS in rat ileum, which is in good correlation with our results.

We also assume that as a result of the adequate oxidative environment and definite baseline expression of HOs and their colocalization with nNOS in the myenteric ganglia in the proximal small intestine, the nitrergic neurons get greater protection and can tolerate hyperglycaemia-related oxidative stress better in the duodenum. This is supported by evidence that despite the impairment of nNOS pathways in STZinduced diabetic rats, the nitrergic myenteric neurons did not die in the duodenum, unlike the other gut segments [9].

Moreover, the highest level of $\mathrm{HO} 1$ and $\mathrm{HO} 2$ expression in the tissue homogenates of the control duodenum (including the smooth muscle layers of the gut wall and the myenteric plexus between them) also highlights an intensified protective environment in this particular gut segment and emphasizes the importance of the neuronal microenvironment $[10,12]$. Microsomal HO activity was also highest in the duodenal mucosa, where absorption of hemoglobin iron is reported to be most effective, and progressively fell in more caudal intestinal segments [55].

In diabetics, the number of $\mathrm{HO} 1$ - or $\mathrm{HO} 2$-representing myenteric ganglia, as well as the number of those ganglia which contain nNOS-HO1 or nNOS-HO2 colocalized neurons, was markedly elevated in the ileum. Likewise, the number of HO1- or HO2-IR and nNOS-HO1 or nNOS-HO2-IR neurons was altered in a region-dependent manner in diabetic rats. The most intensified enhancement was also observed in the ileum of diabetics, which highlights the highest concern of this intestinal region in diabetes-related damage, also predicted in our earlier study [11]. Using a type 1 diabetic rat model to analyse the composition of faecesassociated microbiota, we demonstrated that only ileal samples from diabetic rats exhibited striking, but massive invasion (31\%) of the pathogen genus Klebsiella [11]. It was recently reported that intestinal $\mathrm{HO} 1$ is induced by the enteric microbiota and modulates the macrophages bactericidal activity, suggesting its importance in maintaining homeostasis [56]. On the base of this, we suggest that the diabetes-related massive changes in the composition of the ileal gut microbiota [11] may contribute to the enhanced mucosal immune response and the greatest induction of endogenous $\mathrm{HO}$ system in this particular gut segment.

As regards the details of segment-specific diabetic alterations, in the diabetic ileum, both the HO1-IR and the nNOS-HO1-IR neuronal number was enhanced 7-fold, and the number of nNOS-HO2-IR neurons also increased 6 -fold as compared to controls. Nevertheless, the total number of nNOS neurons decreased in all intestinal segments of diabetics, confirming our earlier findings [9]. Accordingly, much more nitrergic neurons also become HO-IR; thus, many of them start to product $\mathrm{HO}$ enzymes. Moreover, this also means that those nNOS-positive neurons which are not colocalized with HOs will be destroyed. Similar alterations were seen in the colon, where besides a $22 \%$ decrease in the nNOS number, a more than $50 \%$ increase was demonstrated in the number of nNOS-HO1-IR neurons, from which we assume that $\mathrm{HO}$-containing nitrergic neurons enjoy higher protection, whereas the others are heavily affected by diabetic damage. In the diabetic duodenum, besides a decreasing number of nNOS neurons, the number of colocalized myenteric neurons did not alter significantly, leading to the same conclusion. However, based on the study 
of Izbéki et al. [9], in which the duodenum was the only gut segment where the decrease of NADPHd-positive neuronal number was not followed by a decrease in the number of total myenteric neurons, we suppose that in the present study, the reduced number of nNOS neurons means cell loss in the diabetic ileum and colon but a change in neurochemical character in the duodenum. Among others, the neuronal microenvironment-like capillaries of the gut wall or intestinal microbiota of the diabetic duodenum were broadly unharmed $[10,11]$.

Diabetic gastroparesis is a widely researched complication of diabetes, in which the interstitial cells of Cajal responsible for normal gastric emptying are largely damaged [7]. In the diabetic gastric fundus, the number of nNOS-IR neurons was decreased, nNOS expression was downregulated [57], and an impairment in nitrergic relaxation was also reported contributing to the development of diabetic gastroparesis in rats [58]. In mouse models of diabetes, increased expression of antioxidants such as $\mathrm{HO} 1$ protected interstitial cells of Cajal from oxidative stress and reversed diabetic gastroparesis [33]. Recent discovery shows that HO gives neuroprotection by controlling redox formation and reducing production of tumor necrosis factor alpha (TNF $\alpha$ ) [59]. In the light of these findings, the role of the endogenous $\mathrm{HO}$ system in the protection of intestinal motility in diabetics is further strengthened. However, the literary data suggest that TNF may also be capable of exerting opposite effects, which could depend on parameters such as the site, degree, and duration of the ischemic period, the amount of TNF production, the expression level of the two TNF receptors, and the cellular environment of affected neurons [60]. It has been demonstrated that the involvement of the TNF/TNF-receptor system and opposing actions of the two TNF receptors resulting neuronal damage or promoting neuroprotection via different signalling pathways [60-62].

At present, only limited data are available about the diabetes-related expressional changes of HOs in different gut segments. In the STZ rat model, the nitrergic myenteric neurons that also express $\mathrm{HO} 2$ were more resistant to the effects of diabetes and less likely to undergo apoptosis [36]. In the diabetic ileum, this study revealed an increased size of neuronal cell body in nNOS-IR neurons, while HO2-IR neurons remained unaffected. Double-labelling studies confirmed that the diabetes-induced change in size was confined to nNOS-IR neurons that did not contain $\mathrm{HO} 2$.

The induction of the $\mathrm{HO}$ system by agents (such as several redox signals, hypoxia, or endotoxin) has been suggested to be an initial event in the development of an adaptive response to oxidative stress and inflammatory events in type 1 and type 2 diabetes [19, 63-66]. Bacterial endotoxin induces $\mathrm{HO}$ mRNA accumulation [67] and directly stimulates $\mathrm{HO}$ activity in macrophages and the liver [68]. Emerging evidence indicates that the upregulation of the $\mathrm{HO}$ system and related products increases pancreatic beta cell insulin release and reduces hyperglycaemia in different animal models [22]. The HO system is also upregulated in short term diabetes, leading to $\mathrm{HO}$ and $\mathrm{NO}$ interactions, which may modulate vascular function in the retina $[69,70]$. Cheng et al. [71] reported that hypoxia-inducible factor- $1 \alpha$ target genes like $\mathrm{HO}$ also contribute to retinal neuroprotection. It has also been demonstrated that $\mathrm{NO}$ and $\mathrm{NO}$ donors are capable of inducing $\mathrm{HO} 1$ protein expression, in a mechanism depending on the de novo synthesis of RNA and protein. Thus, it is postulated that NO may serve as a signaling molecule in the modulation of the tissue stress response [72].

\section{Conclusions}

In conclusion, our present findings emphasize that the endogenous $\mathrm{HO}$ system of the GI tract is also a target of diabetic damage. In addition, the evidences published here have revealed for the first time the intestinal region-dependent induction of the $\mathrm{HO}$ system as well as the segment-specific enhanced colocalization of $\mathrm{HO} 1$ and $\mathrm{HO} 2$ with nNOS in myenteric neurons. Obviously, the functional consequences of these diabetes-related alterations, namely, the possible interactions between the carbon monoxide and nitric oxide pathways produced by them in enteric neurons to regulate various GI functions demand further investigations.

\section{Abbreviations}

ELISA: Enzyme-linked immunosorbent assays

GI: Gastrointestinal

$\mathrm{HO}$ : Heme oxygenase

IR: Immunoreactive

nNOS: Neuronal nitric oxide synthase

PB: $\quad$ Phosphate buffer

ROS: Reactive oxygen species

STZ: Streptozotocin.

\section{Conflicts of Interest}

The authors declare that there is no conflict of interest regarding the publication of this paper.

\section{Authors' Contributions}

Lalitha Chandrakumar and Mária Bagyánszki are both co-first authors.

\section{Acknowledgments}

The authors thank their teacher, Professor Éva Fekete, for her valuable support and guidance in the research work. The present study was supported by the Hungarian Scientific Research Fund, OTKA grant PD 108309 (Nikolett Bódi); by the János Bolyai Research Scholarship of the Hungarian Academy of Sciences (Mária Bagyánszki); and by the Stipendium Hungaricum Scholarship 2015-SH-500041, Tempus Public Foundation (Lalitha Chandrakumar).

\section{References}

[1] S. Wild, G. Roglic, A. Green, R. Sicree, and H. King, "Global prevalence of diabetes: estimates for the year 2000 and projections for 2030," Diabetes Care, vol. 27, no. 5, pp. 1047-1053, 2004. 
[2] F. A. Sloan, M. A. Bethel, D. Ruiz Jr., A. M. Shea, and M. N. Feinglos, "The growing burden of diabetes mellitus in the US elderly population," Archives of Internal Medicine, vol. 168, no. 2, pp. 192-199, 2008.

[3] A. Onat, "Metabolic syndrome: nature, therapeutic solutions and options," Expert Opinion on Pharmacotherapy, vol. 12, pp. 1887-1900, 2011.

[4] M. M. Okamoto, G. F. Anhê, R. Sabino-Silva et al., "Intensive insulin treatment induces insulin resistance in diabetic rats by impairing glucose metabolism-related mechanisms in muscle and liver," The Journal of Endocrinology, vol. 211, pp. 55-64, 2011.

[5] P. Bytzer, N. J. Talley, M. Leemon, L. J. Young, M. P. Jones, and M. Horowitz, "Prevalence of gastrointestinal symptoms associated with diabetes mellitus: a population-based survey of 15,000 adults," Archives of Internal Medicine, vol. 161, no. 16, pp. 1989-1996, 2001.

[6] A. Rosztóczy, R. Róka, T. T. Várkonyi et al., "Regional differences in the manifestation of gastrointestinal motor disorders in type 1 diabetic patients with autonomic neuropathy," Zeitschrift für Gastroenterologie, vol. 42, no. 11, pp. 1295-1300, 2004.

[7] T. Ördög, Y. Hayashi, and S. J. Gibbons, "Cellular pathogenesis of diabetic gastroenteropathy," Minerva Gastroenterologica e Dietologica, vol. 55, no. 3, pp. 315-343, 2009.

[8] C. C. Watkins, A. Sawa, S. Jaffrey et al., "Insulin restores neuronal nitric oxide synthase expression and function that is lost in diabetic gastropathy," The Journal of Clinical Investigation, vol. 106, no. 3, pp. 373-384, 2000.

[9] F. Izbéki, T. Wittman, A. Rosztóczy et al., "Immediate insulin treatment prevents gut motility alterations and loss of nitrergic neurons in the ileum and colon of rats with streptozotocininduced diabetes," Diabetes Research and Clinical Practice, vol. 80, no. 2, pp. 192-198, 2008.

[10] N. Bódi, P. Talapka, M. Z. Poles et al., "Gut region-specific diabetic damage to the capillary endothelium adjacent to the myenteric plexus," Microcirculation, vol. 19, no. 4, pp. 316326, 2012.

[11] R. Wirth, N. Bódi, G. Maróti et al., "Regionally distinct alterations in the composition of the gut microbiota in rats with streptozotocin-induced diabetes," PLoS One, vol. 9, no. 12, article e110440, 2014.

[12] M. Bagyánszki and N. Bódi, "Diabetes-related alterations in the enteric nervous system and its microenvironment," World Journal of Diabetes, vol. 3, no. 5, pp. 80-93, 2012.

[13] Z. Jancsó, N. Bódi, B. Borsos, É. Fekete, and E. Hermesz, “Gut region-specific accumulation of reactive oxygen species leads to regionally distinct activation of antioxidant and apoptotic marker molecules in rats with STZ-induced diabetes," The International Journal of Biochemistry \& Cell Biology, vol. 62, pp. 125-131, 2015.

[14] M. S. Rendell and L. Jovanovic, "Targeting postprandial hyperglycemia," Metabolism, vol. 55, no. 9, pp. 1263-1281, 2006.

[15] C. Tang, P. Han, A. I. Oprescu et al., "Evidence for a role of superoxide generation in glucose-induced beta-cell dysfunction in vivo," Diabetes, vol. 56, no. 11, pp. 2722-2731, 2007.

[16] E. Voukali, H. R. Shotton, and J. Lincoln, "Selective responses of myenteric neurons to oxidative stress and diabetic stimuli," Neurogastroenterology and Motility, vol. 23, no. 10, pp. 964e411, 2011.

[17] C. R. Bruce, A. L. Carey, J. A. Hawley, and M. A. Febbraio, "Intramuscular heat shock protein 72 and heme oxygenase-1
mRNA are reduced in patients with type 2 diabetes: evidence that insulin resistance is associated with a disturbed antioxidant defense mechanism," Diabetes, vol. 52, no. 9, pp. 23382345, 2003.

[18] A. L'Abbate, D. Neglia, C. Vecoli et al., "Beneficial effect of heme oxygenase-1 expression on myocardial ischemiareperfusion involves an increase in adiponectin in mildly diabetic rats," American Journal of Physiology. Heart and Circulatory Physiology, vol. 293, no. 6, pp. H3532-H3541, 2007.

[19] J. F. Ndisang, "Role of heme oxygenase in inflammation, insulin-signalling, diabetes and obesity," Mediators of Inflammation, vol. 2010, Article ID 359732, 18 pages, 2010.

[20] K. Schümann, N. Herbach, C. Kerling et al., "Iron absorption and distribution in $\mathrm{TNF}^{\triangle \mathrm{ARE} /+}$ mice, a model of chronic inflammation," Journal of Trace Elements in Medicine and Biology, vol. 24, no. 1, pp. 58-66, 2010.

[21] X. Zhu, W. G. Fan, D. P. Li, H. Kung, and M. C. Lin, "Heme oxygenase- 1 system and gastrointestinal inflammation: a short review," World Journal of Gastroenterology, vol. 17, no. 38, pp. 4283-4288, 2011.

[22] S. Tiwari and J. F. Ndisang, "The heme oxygenase system and type-1 diabetes," Current Pharmaceutical Design, vol. 20, no. 9, pp. 1328-1337, 2014.

[23] M. Chang, J. Xue, V. Sharma, and A. Habtezion, "Protective role of hemeoxygenase-1 in gastrointestinal diseases," Cellular and Molecular Life Sciences, vol. 72, no. 6, pp. 1161-1173, 2015.

[24] S. W. Ryter, J. Alam, and A. M. Choi, "Heme oxygenase-1/carbon monoxide: from basic science to therapeutic applications," Physiological Reviews, vol. 86, no. 2, pp. 583-650, 2006.

[25] N. G. Abraham, P. L. Tsenovoy, J. McClung, and G. S. Drummond, "Heme oxygenase: a target gene for anti-diabetic and obesity," Current Pharmaceutical Design, vol. 14, no. 5, pp. 412-421, 2008.

[26] N. G. Abraham and A. Kappas, "Pharmacological and clinical aspects of heme oxygenase," Pharmacological Reviews, vol. 60, no. 1, pp. 79-127, 2008.

[27] M. D. Maines, "The heme oxygenase system: a regulator of second messenger gases," Annual Review of Pharmacology and Toxicology, vol. 37, pp. 517-554, 1997.

[28] D. Burger, F. Xiang, L. Hammoud, X. Lu, and Q. Feng, "Role of heme oxygenase- 1 in the cardioprotective effects of erythropoietin during myocardial ischemia and reperfusion," American Journal of Physiology Heart and Circulatory Physiology, vol. 296, no. 1, pp. H84-H93, 2009.

[29] A. Y. Chang, J. Y. Chan, H. L. Cheng, C. Y. Tsai, and S. H. Chan, "Hypoxia-inducible factor $1 /$ heme oxygenase 1 cascade as upstream signals in the prolife role of heat shock protein 70 at rostral ventrolateral medulla during experimental brain stem death," Shock, vol. 32, no. 6, pp. 651-658, 2009.

[30] K. L. Cooper, K. J. Liu, and L. G. Hudson, "Enhanced ROS production and redox signaling with combined arsenite and UVA exposure: contribution of NADPH oxidase," Free Radical Biology and Medicine, vol. 47, no. 4, pp. 381-388, 2009.

[31] R. V. Pereira, M. H. de Miranda-Neto, I. D. da Silva Souza, and J. N. Zanoni, "Vitamin E supplementation in rats with experimental diabetes mellitus: analysis of myosin- $\mathrm{V}$ and nNOS immunoreactive myenteric neurons from terminal ileum," Journal of Molecular Histology, vol. 39, pp. 595603, 2008. 
[32] R. V. Pereira, E. A. Tronchini, C. M. Tashima, E. P. Alves, M. M. Lima, and J. N. Zanoni, "L-glutamine supplementation prevents myenteric neuron loss and has gliatrophic effects in the ileum of diabetic rats," Digestive Diseases and Sciences, vol. 56, pp. 3507-3516, 2011.

[33] K. M. Choi, S. J. Gibbons, T. V. Nguyen et al., "Heme oxygenase-1 protects interstitial cells of Cajal from oxidative stress and reverses diabetic gastroparesis," Gastroenterology, vol. 135, pp. 2055-2064.e1-2, 2008.

[34] A. A. Elmarakby, J. Faulkner, B. Baban, M. A. Saleh, and J. C. Sullivan, "Induction of hemeoxygenase-1 reduces glomerular injury and apoptosis in diabetic spontaneously hypertensive rats," American Journal of Physiology Renal Physiology, vol. 302, no. 7, pp. F791-F800, 2012.

[35] S. C. Lee, S. H. Han, J. J. Li et al., "Induction of heme oxygenase-1 protects against podocyte apoptosis under diabetic conditions," Kidney International, vol. 76 , no. 8, pp. 838-848, 2009.

[36] H. R. Shotton and J. Lincoln, "Diabetes only affects nitric oxide synthase-containing myenteric neurons that do not contain heme oxygenase 2," Brain Research, vol. 1068, pp. 248-256, 2006.

[37] H. Farhangkhoee, Z. A. Khan, S. Mukherjee et al., "Heme oxygenase in diabetes-induced oxidative stress in the heart," Journal of Molecular and Cellular Cardiology, vol. 35, no. 12, pp. 1439-1448, 2003.

[38] S. Chen, Z. A. Khan, Y. Barbin, and S. Chakrabarti, "Prooxidant role of heme oxygenase in mediating glucoseinduced endothelial cell damage," Free Radical Research, vol. 38, no. 12, pp. 1301-1310, 2004.

[39] J. L. da Silva, T. Morishita, B. Escalante et al., "Dual role of heme oxygenase in epithelial cell injury: contrasting effects of short-term and long-term exposure to oxidant stress," The Journal of Laboratory and Clinical Medicine, vol. 128, no. 3, pp. 290-296, 1996.

[40] H. Hayashi, R. Takahashi, T. Nishi, M. Sakamoto, and Y. Benno, "Molecular analysis of jejunal, ileal, caecal and rectosigmoidal human colonic microbiota using $16 \mathrm{~S}$ rRNA gene libraries and terminal restriction fragment length polymorphism," Journal of Medical Microbiology, vol. 54, Part 11, pp. 1093-1101, 2005.

[41] M. Arumugam, J. Raes, E. Pelletier et al., "Enterotypes of the human gut microbiome," Nature, vol. 473, no. 7346, pp. 174-180, 2011.

[42] A. van der Vliet, T. J. Tuinstra, and A. Bast, "Modulation of oxidative stress in the gastrointestinal tract and effect on rat intestinal motility," Biochemical Pharmacology, vol. 38, no. 17, pp. 2807-2818, 1989.

[43] A. J. Burns and V. Pachnis, "Development of the enteric nervous system: bringing together cells, signals and genes," Neurogastroenterology and Motility, vol. 21, no. 2, pp. 100$102,2009$.

[44] R. Doodnath, M. Wride, and P. Puri, "The spatiotemporal patterning of Hoxa9 and Hoxa13 in the developing zebrafish enteric nervous system," Pediatric Surgery International, vol. 28, no. 2, pp. 115-121, 2012.

[45] N. Larsen, F. K. Vogensen, F. W. van den Berg et al., "Gut microbiota in human adults with type 2 diabetes differs from nondiabetic adults," PLoS One, vol. 5, no. 2, article e9085, 2010.

[46] R. Burcelin, M. Serino, C. Chabo, V. BlascoBaque, and J. Amar, "Gut microbiota and diabetes: from pathogenesis to therapeutic perspective," Acta Diabetologica, vol. 48, no. 4, pp. 257-273, 2011.

[47] A. Brune, D. Emerson, and J. A. Breznak, "The termite gut microflora as an oxygen sink: microelectrode determination of oxygen and $\mathrm{pH}$ gradients in guts of lower and higher termites," Applied and Environmental Microbiology, vol. 61, no. 7, pp. 2681-2687, 1995.

[48] L. M. Sanders, C. E. Henderson, M. Y. Hong et al., "Pro-oxidant environment of the colon compared to the small intestine may contribute to greater cancer susceptibility," Cancer Letters, vol. 208, no. 2, pp. 155-161, 2004.

[49] M. L. Circu and T. Y. Aw, "Redox biology of the intestine," Free Radical Research, vol. 45, no. 11-12, pp. 1245-1266, 2011.

[50] R. Battish, G. Y. Cao, R. B. Lynn, S. Chakder, and S. Rattan, "Heme oxygenase-2 distribution in anorectum: colocalization with neuronal nitric oxide synthase," American Journal of Physiology Gastrointestinal and Liver Physiology, vol. 278, no. 1, pp. G148-G155, 2000.

[51] K. Inoue, T. Takahashi, K. Uehara et al., "Protective role of heme oxygenase 1 in the intestinal tissue injury in hemorrhagic shock in rats," Shock, vol. 29, no. 2, pp. 252-261, 2008.

[52] H. Fujii, T. Takahashi, K. Nakahira et al., "Protective role of heme oxygenase- 1 in the intestinal tissue injury in an experimental model of sepsis," Critical Care Medicine, vol. 31, no. 3, pp. 893-902, 2003.

[53] S. M. Miller, D. Reed, M. G. Sarr, G. Farrugia, and J. H. Szurszewski, "Haem oxygenase in enteric nervous system of human stomach and jejunum and co-localization with nitric oxide synthase," Neurogastroenterology and Motility, vol. 13, no. 2, pp. 121-131, 2001.

[54] M. E. Donat, K. Wong, W. A. Staines, and A. Krantis, "Heme oxygenase immunoreactive neurons in the rat intestine and their relationship to nitrergic neurons," Journal of the Autonomic Nervous System, vol. 77, no. 1, pp. 4-12, 1999.

[55] S. B. Raffin, C. H. Woo, K. T. Roost, D. C. Price, and R. Schmid, "Intestinal absorption of hemoglobin iron-heme cleavage by mucosal heme oxygenase," The Journal of Clinical Investigation, vol. 54, no. 6, pp. 1344-1352, 1974.

[56] J. C. Onyiah, S. Z. Sheikh, N. Maharshak, L. E. Otterbein, and S. E. Plevy, "Heme oxygenase-1 and carbon monoxide regulate intestinal homeostasis and mucosal immune responses to the enteric microbiota," Gut Microbes, vol. 5, no. 2, pp. 220-224, 2014.

[57] H. L. Lu, X. Huang, Y. S. Wu et al., "Gastric nNOS reduction accompanied by natriuretic peptides signaling pathway upregulation in diabetic mice," World Journal of Gastroenterology, vol. 20, no. 16, pp. 4626-4635, 2014.

[58] P. R. Gangula, S. Mukhopadhyay, K. Ravella et al., "Tetrahydrobiopterin $\left(\mathrm{BH}_{4}\right)$, a cofactor for nNOS, restores gastric emptying and nNOS expression in female diabetic rats," American Journal of Physiology. Gastrointestinal and Liver Physiology, vol. 298, pp. G692-G699, 2010.

[59] U. Shefa, S. G. Yeo, M. S. Kim et al., "Role of gasotransmitters in oxidative stresses, neuroinflammation, and neuronal repair," BioMed Research International, vol. 2017, Article ID 1689341, 15 pages, 2017.

[60] V. Fontaine, S. Mohand-Said, N. Hanoteau, C. Fuchs, K. Pfizenmaier, and U. Eisel, "Neurodegenerative and neuroprotective effects of tumor necrosis factor (TNF) in retinal ischemia: opposite roles of TNF receptor 1 and TNF receptor 2," The Journal of Neuroscience, vol. 22, no. 7, article RC216, 2002. 
[61] N. G. Carlson, W. A. Wieggel, J. Chen, A. Bacchi, S. W. Rogers, and L. C. Gahring, "Inflammatory cytokines IL- $1 \alpha$, IL- $1 \beta$, IL6 , and TNF- $\alpha$ impart neuroprotection to an excitotoxin through distinct pathways," Journal of Immunology, vol. 163, no. 7, pp. 3963-3968, 1999.

[62] I. Figiel, "Pro-inflammatory cytokine TNF- $\alpha$ as a neuroprotective agent in the brain," Acta Neurobiologiae Experimentalis (Wars), vol. 68, no. 4, pp. 526-534, 2008.

[63] N. G. Abraham, Y. Lavrovsky, M. L. Schwartzman et al., "Transfection of the human heme oxygenase gene into rabbit coronary microvessel endothelial cells: protective effect against heme and hemoglobin toxicity," Proceedings of the National Academy of Sciences of the United States of America, vol. 92, no. 15 , pp. 6798-6802, 1995.

[64] R. Motterlini, C. J. Green, and R. Foresti, "Regulation of heme oxygenase- 1 by redox signals involving nitric oxide," Antioxidants \& Redox Signaling, vol. 4, no. 4, pp. 615-624, 2002.

[65] S. Satarug and M. R. Moore, "Emerging roles of cadmium and heme oxygenase in type- 2 diabetes and cancer susceptibility," The Tohoku Journal of Experimental Medicine, vol. 228, no. 4, pp. 267-288, 2012.

[66] G. Negi, V. Nakkina, P. Kamble, and S. S. Sharma, "Heme oxygenase-1, a novel target for the treatment of diabetic complications: focus on diabetic peripheral neuropathy," Pharmacological Research, vol. 102, pp. 158-167, 2015.

[67] M. Rizzardini, M. Carelli, M. R. Cabello Porras, and L. Cantoni, "Mechanisms of endotoxin-induced haem oxygenase mRNA accumulation in mouse liver: synergism by glutathione depletion and protection by $\mathrm{N}$-acetylcysteine," The Biochemical Journal, vol. 304, Part 2, pp. 477-483, 1994.

[68] D. Gemsa, C. H. Woo, H. H. Fudenberg, and R. Schmid, "Stimulation of heme oxygenase in macrophages and liver by endotoxin," The Journal of Clinical Investigation, vol. 53, no. 2, pp. 647-651, 1974.

[69] M. Cukiernik, S. Mukherjee, D. Downey, and S. Chakabarti, "Heme oxygenase in the retina in diabetes," Current Eye Research, vol. 27, no. 5, pp. 301-308, 2003.

[70] Á. Castilho, C. A. Aveleira, E. C. Leal et al., "Heme oxygenase-1 protects retinal endothelial cells against high glucose- and oxidative/nitrosative stress-induced toxicity," PLoS One, vol. 7, no. 8, article e42428, 2012.

[71] L. Cheng, H. Yu, N. Yan, K. Lai, and M. Xiang, "Hypoxia-inducible factor- $1 \alpha$ target genes contribute to retinal neuroprotection," Frontiers in Cellular Neuroscience, vol. 11, p. 20, 2017.

[72] R. Foresti and R. Motterlini, "The heme oxygenase pathway and its interaction with nitric oxide in the control of cellular homeostasis," Free Radical Research, vol. 31, no. 6, pp. 459475, 1999. 


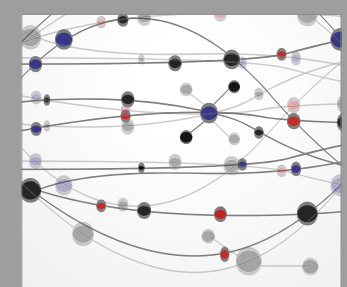

The Scientific World Journal
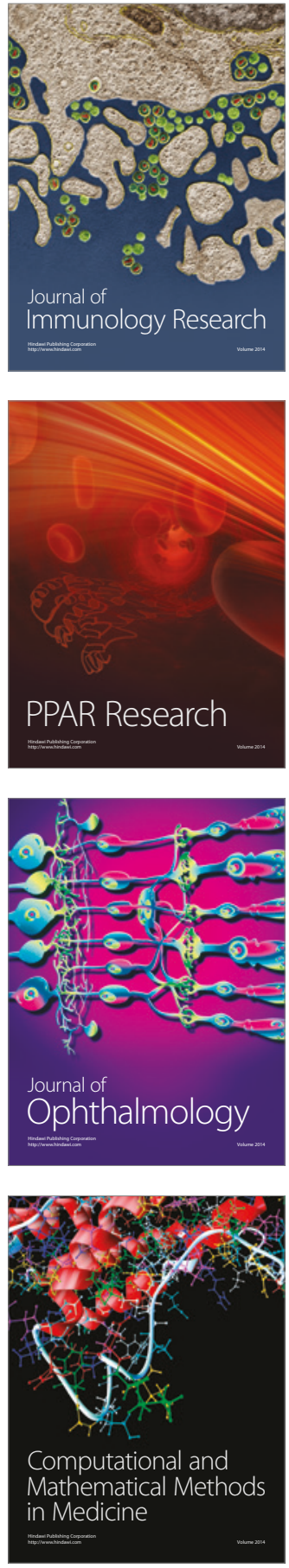

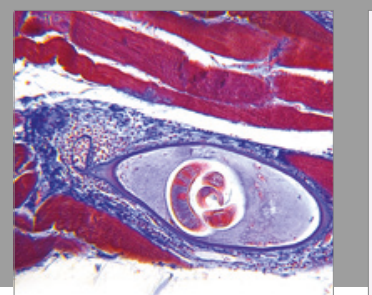

Gastroenterology Research and Practice
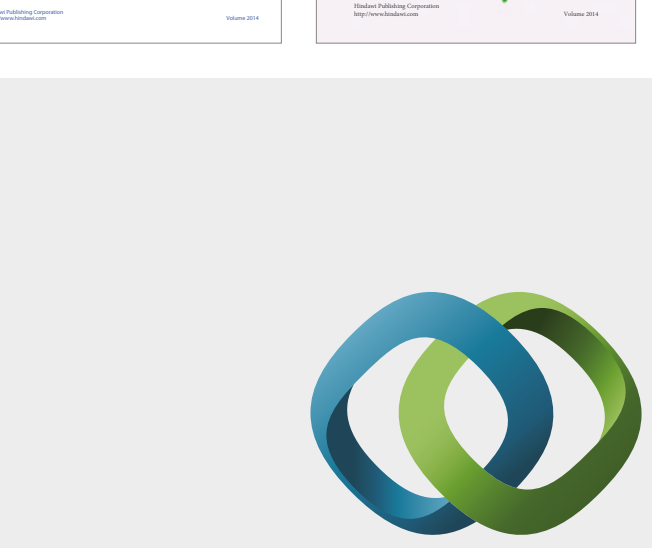

\section{Hindawi}

Submit your manuscripts at

https://www.hindawi.com
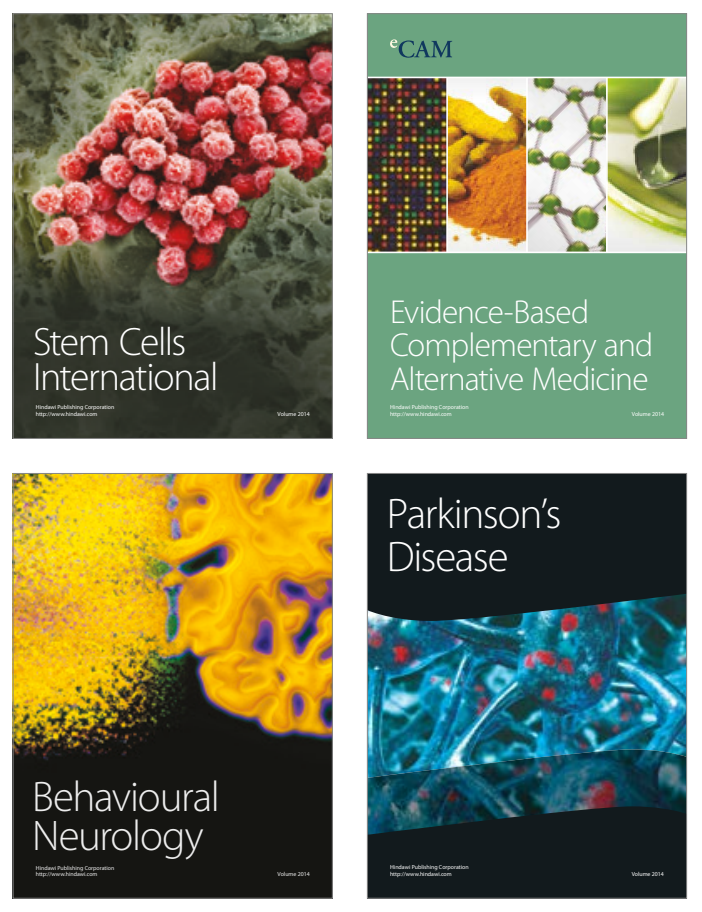
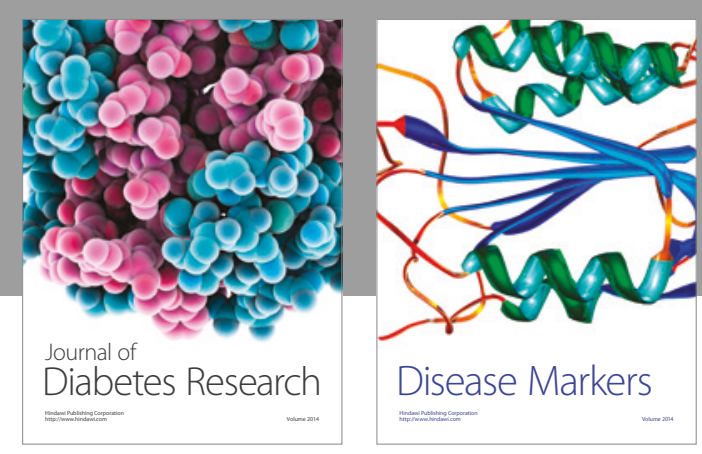

Disease Markers
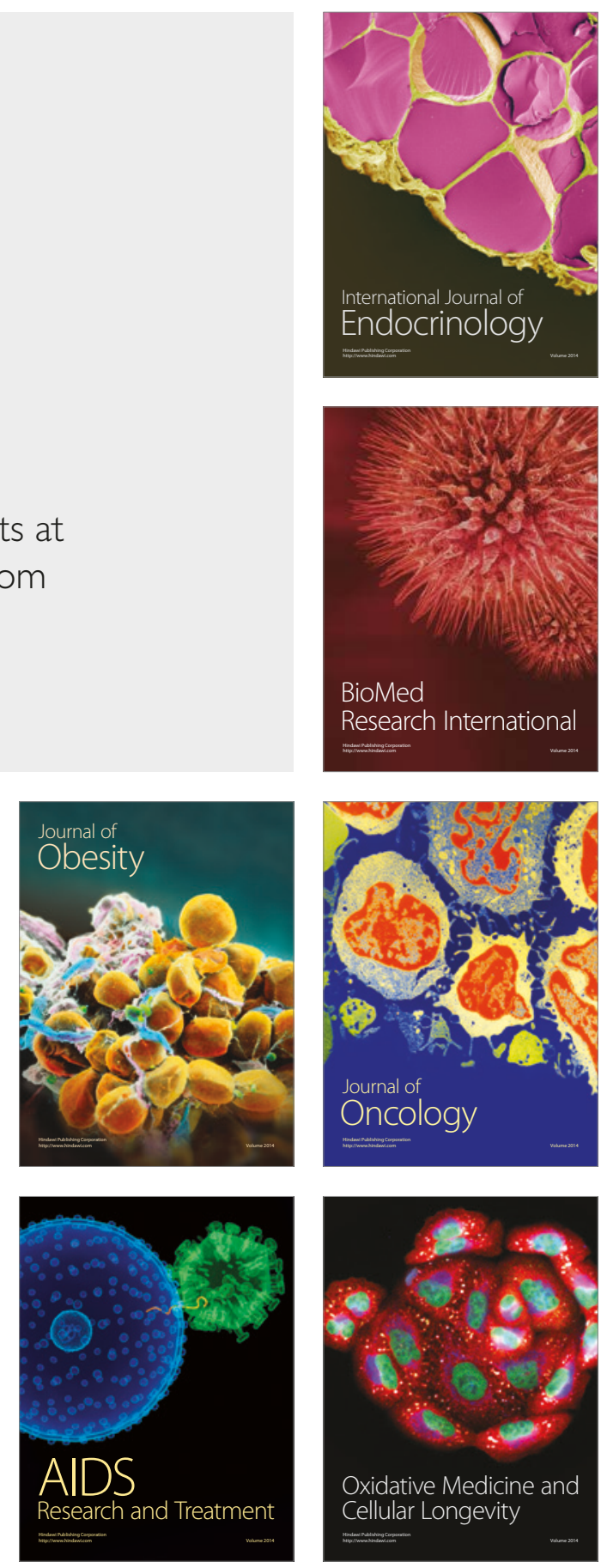